\section{Red sky at night: Long-wavelength photochemistry in the atmosphere}

\author{
D . J . D O N A L D S O N* \\ University of Toronto, Canada
}

C H R I S T I A N G E O R G E

Université De Lyon, France and Institut De Recherches Sur La Catalyse Et L'Environnement De Lyon, Villeurbanne, France

VERONICA VAIDA

University of Colorado, Boulder, Colorado

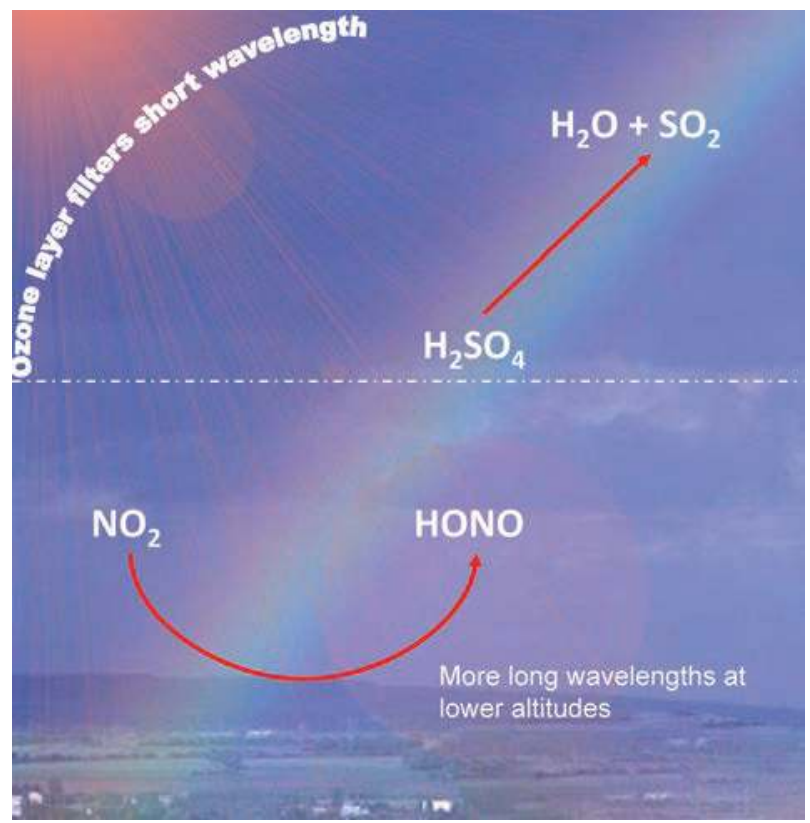

Chemical reactions occurring in the atmosphere exert a key influence on air quality at the local and regional scales. On a global scale they have a strong affect on climate, through formation and removal of greenhouse gases, as well as driving cloud formation. Earth's atmosphere is composed roughly $99 \%$ of two gases: molecular nitrogen $\left(\mathrm{N}_{2} ; \sim 78 \%\right)$ and molecular oxygen $\left(\mathrm{O}_{2} ; \sim 21 \%\right)$, with variable and highly local amounts of water vapor $\left(\mathrm{H}_{2} \mathrm{O}_{[\mathrm{v}]}\right.$; up to a few percent), as well as various trace gas species (such as $\mathrm{CO}_{2}$, presently at a concentration of a little less than $0.04 \%$ ). On Earth, "atmospheric chemistry" involves chemical species present only in trace amounts, and is almost exclusively oxidative. Because $\mathrm{O}_{2}$ is not particularly reactive toward closed shell compounds (those without free electrons), chemistry is initiated by the formation of reactive free radicals, which are then oxidized via the addition of molecular oxygen. Since this addition reaction itself generates free radicals, it is but one such reaction in a sequence, which together comprise an oxidizing chain reaction system in the atmosphere. There is a multitude of organic species in the atmosphere, the most abundant of which is methane $\left(\mathrm{CH}_{4}\right)$, which are all eventually oxidized to $\mathrm{CO}_{2}$ and $\mathrm{H}_{2} \mathrm{O}$, either by gas or aerosol phase processes.

Ultimately, free radicals in the atmosphere are all generated photochemically with short wavelength radiation. This can be a direct process, such as that shown for formaldehyde in reactions $\mathrm{R} 1-\mathrm{R} 3$ below, or indirect, such as the formation of $\mathrm{OH}$ through reaction of electronically excited $\mathrm{O}$ atoms which efficiently react with $\mathrm{H}_{2} \mathrm{O}$ and organic molecules, as illustrated in reactions R4 and R5.

$$
\begin{gathered}
\mathrm{HCHO}+\mathrm{h} v \rightarrow \mathrm{H}+\mathrm{HCO} \\
\mathrm{H}+\mathrm{O}_{2}+\mathrm{M} \rightarrow \mathrm{HO}_{2}+\mathrm{M} \\
\mathrm{HCO}+\mathrm{O}_{2} \rightarrow \mathrm{HO}_{2}+\mathrm{CO} \\
\mathrm{O}_{3}+\mathrm{h} v(\lambda<305 \mathrm{~nm}) \rightarrow \mathrm{O}\left({ }^{1} \mathrm{D}\right)+\mathrm{O}_{2} \\
\mathrm{O}\left({ }^{1} \mathrm{D}\right)+\mathrm{H}_{2} \mathrm{O} \rightarrow 2 \mathrm{OH}
\end{gathered}
$$

In the presence of high levels of $\mathrm{NO} x\left(=\mathrm{NO}+\mathrm{NO}_{2}\right)$ the $\mathrm{HO}_{2}$ radicals formed in reactions such as $\mathrm{R} 2$ and $\mathrm{R} 3$ are rapidly converted to the hydroxyl radical $(\mathrm{OH} \bullet)$, which is very reactive toward most organic and many inorganic compounds; these reactions of $\mathrm{OH}$ are the primary formation mechanism for radicals in the atmosphere. Similar pathways will also exist in the atmospheric condensed phase (aerosols and clouds) where multiple reactions initiated by UV light will produce radicals or radical anions, and lead to the degradation of both organic and inorganic compounds (as highlighted by the formation of acid rain).

Hydroxyl radicals, despite their low $\left(10^{6}\right.$ to $10^{7}$ molecules $\mathrm{cm}^{-3}$ ) daytime atmospheric concentrations, are the most important reactive species in the atmosphere, controlling the concentration of pollutants and greenhouse gases. Understanding what controls the abundance of these radicals is paramount for accurately modeling the atmosphere's oxidizing capacity and to predict future change. Accordingly, over the decades since Hiram Levy (1) highlighted the central role played by $\mathrm{OH}$ radicals in the troposphere, great attention has been given to understanding their chemistry, which is now fully described in textbooks of environmental and atmospheric chemistry (2).

Quite recently, with advances in gas-phase measurement techniques, it has become possible to directly monitor the $\mathrm{OH}$ concentration in the troposphere along with several other reactive radical species (such as $\mathrm{HO}_{2}, \mathrm{RO}_{2}, \mathrm{NO}_{3}$, etc.) $(3,4)$. Taking advantage of these developments, several field campaigns have highlighted unpredicted levels of $\mathrm{OH}$ over the pristine Amazon forest (5) and in the Pearl River Delta, China (6). These studies point to unknown $\mathrm{OH}$ sources and/ or previously unknown chemical processes, suggesting missing sources or cycling of radicals, and requiring new 
ideas and approaches which go beyond textbook knowledgefrom the UV to the visible and beyond!

For this reason, understanding all possible initiation reactions, such as $\mathrm{R} 1$ and $\mathrm{R} 4$, is still of fundamental importance to our ability to predict and model atmospheric chemical processes. These photochemical reactions are analyzed as first-order kinetic processes, with a photochemical rate coefficient, $J$, which depends upon the absorption coefficient $\sigma(\lambda)$ of the absorbing compound, the quantum yield for the dissociation $\phi(\lambda)$, and the available photon flux $I(\lambda)$ :

$$
J=\int_{\lambda} \sigma(\lambda) \varphi(\lambda) I(\lambda) d \lambda
$$

This expression encapsulates the principle that, in order to dissociate, a compound must absorb available radiation in a wavelength region in which this photochemistry can and will occur. Because typical chemical bond energies are in the $100 \mathrm{sJ} \mathrm{mol}^{-1}$ range, the conventional picture requires ultraviolet solar radiation to effect bond-cleaving photochemistry, such as illustrated in $\mathrm{R} 1$ and $\mathrm{R} 4$, in the atmosphere.

Absorption of UV solar radiation by $\mathrm{O}_{2}$ in the upper atmosphere, and by $\mathrm{O}_{3}$ in the upper-mid stratosphere, gives an altitude and solar zenith angle dependence to the wavelengths of light available in the atmosphere. The longer pathways associated with higher altitudes and larger zenith angles (i.e., as the sun approaches the horizon) mean that shorter wavelengths are attenuated for these situations. This fact gives rise to photochemistry which depends on altitude, season, and time of day. At the lowest altitudes, essentially all of the higher energy UV radiation is attenuated, leaving light of $\lambda>290 \mathrm{~nm}$ to effect any photochemistry. Light in the visible and longer wavelength regions $(\lambda>400 \mathrm{~nm})$ is very much more abundant than higher energy radiation (in the UV region) at all altitudes and solar zenith angles. Although visible radiation may be sufficiently energetic to rupture weaker chemical bonds, it is generally not in the correct wavelength range to excite electronic transitions of atmospherically relevant molecules. Therefore, light in this spectral region is not usually considered as a driving force in atmospheric chemistry.

However, in the mid-1990s, in response to model predictions which disagreed with measured stratospheric $\mathrm{HO}_{x}$, especially at high solar zenith angle (7), two of the present authors suggested that overtone-mediated photodissociation of $\mathrm{HO}_{x}$-containing species by red light (i.e., in the visible and near-IR regions) could be important (8). Inclusion of the additional $\mathrm{HO}_{x}$ produced by this novel (to atmospheric chemists) form of photochemistry reproduced the "red sky" temporal profiles of the observations and went some way toward resolving the discrepancies between modeled and measured $\mathrm{HO}_{x}(4,8-12)$. In the following, we discuss some recent work which further explores this mechanism, as well as introducing a second, hitherto little-considered atmospheric mechanism: radical formation via photosensitized reactions. With examples of reactions driven by these mechanisms, we show that long wavelength solar radiation may play an important role in atmospheric chemistry, especially in the production of oxidants.

\section{Overtone-driven Chemistry}

As indicated above, one way in which long wavelength radiation may promote atmospheric radical formation is through absorption by a gas-phase molecule into high-lying vibrational levels. If these levels contain sufficient energy to induce reaction, radicals may be formed $(13,14)$. The reaction may either be a unimolecular dissociation of the initially excited molecule, or a bimolecular reaction with another species which is rendered energetically favorable via excitation by red light.

In polyatomic molecules containing $\mathrm{O}-\mathrm{H}, \mathrm{C}-\mathrm{H}$, and $\mathrm{N}-\mathrm{H}$ groups, the small mass of the hydrogen atom means that $\mathrm{X}-\mathrm{H}$ stretching frequencies are considerably higher than those of other vibrational modes. This feature and the generally large anharmonicities associated with such $\mathrm{X}-\mathrm{H}$ stretches, give rise to absorption transitions to higher vibrational levels becoming less "forbidden" (and hence stronger) than for other types of overtone absorption. At higher vibrational levels these transitions become sufficiently separated from the rest of the molecular vibrations to be treated by the "local mode" approximation, in which each $\mathrm{X}-\mathrm{H}$ vibration is taken to be an independent anharmonic oscillator (15). Spectroscopically, the latter condition means that overtone absorptions are well separated from other absorptions; Figure 1 illustrates this for nitric acid $\left(\mathrm{HNO}_{3}\right)$, where the transitions to $v=3$ and $v=4$ of the $\mathrm{OH}$ stretch are shown (16).

As shown in this figure, vibrational overtone transitions to states with 3-6 quanta of $\mathrm{OH}$ stretch occur in the near-IR (NIR) to visible region of the spectrum. The absorption intensities for such $\Delta v=n$ transitions are much smaller than those to electronic states, and decrease, typically by an order of magnitude, with increasing $n$. These levels are sufficiently energetic to cause cleavage of weak bonds in several atmospherically important molecules, such as $\mathrm{HNO}_{x}(\mathrm{HONO}$, $\mathrm{HONO}_{2}, \mathrm{HO}_{2} \mathrm{NO}_{2}$ ), which may then cause their dissociation to $\mathrm{HO}_{x}+\mathrm{NO}_{x}(11,12,14,17,18)$. This process is indicated in Figure 1 for $\mathrm{HNO}_{3}$, where the initial excitation in $\mathrm{OH}$ stretching motion, at energies above the dissociation limit to $\mathrm{OH}+\mathrm{NO}_{2}$, may be transformed to motion along the $\mathrm{N}-\mathrm{O}$ dissociation coordinate. In the case of peroxynitric acid $\left(\mathrm{HOONO}_{2}\right)$ the dissociation limit is reached at the $v=3$ level of the $\mathrm{OH}$ stretch, with thermally assisted dissociation possible from the $v=2$ level as well (12). Overtone-initiated dissociation of this molecule from $\mathrm{OH}$ vibrational levels $v \geq$ 2 has been shown to be an important source for $\mathrm{HO}_{x}$ in the free troposphere (9) and lower stratosphere $(4,10,19)$, resolving a major discrepancy between measurements and models.

Recent laboratory studies have responded to suggestions based on theoretical modeling that red-light initiated chemistry is possible in many other acids and alcohols whose excited states lie far in the UV region of the spectrum, outside the atmospheric window. In addition to direct bond cleavage, molecules with a high degree of internal excitation may undergo rearrangements, followed by dissociation to molecular products. For example, sulfuric acid $\left(\mathrm{H}_{2} \mathrm{SO}_{4}\right)$ has been predicted to undergo a unimolecular dehydration reaction to form $\mathrm{SO}_{3}$ and $\mathrm{H}_{2} \mathrm{O}$ following excitation to $v \geq 4$ of an $\mathrm{OH}$ stretching vibration-corresponding to energies well below the weakest individual bond in the acid $(20-22)$.

Overtone pumping has also been predicted to lead to $\mathrm{HF}$ elimination from trifluoroacetic acid $\left(\mathrm{F}_{3} \mathrm{CCOOH}\right)(23)$ and perfluoroalcohols (24), and decarboxylation of malonic $\left(\mathrm{CH}_{2}[\mathrm{COOH})_{2}\right)(25)$ and pyruvic $\left(\mathrm{CH}_{3} \mathrm{COCOOH}\right)(26)$ acids. Recent laboratory studies and "on the fly" dynamical simulations have investigated the long wavelength photochemistry of pyruvic $(26,27)$ and glyoxylic $(\mathrm{HCOCOOH})$ $(28,29)$ acids, and shown that overtone-driven decarboxylation is both rapid and efficient. In both of these examples, photoreaction occurs in less than $10^{-12}$ seconds-much more rapidly than collisional deactivation-and generates highly reactive carbene radicals in addition to the $\mathrm{CO}_{2}$ product. Such hydrocarbon radical-generating processes will give rise both to increased $\mathrm{HO}_{x}$ production and to new aerosol particle formation, via condensation of the oxidized products. This will be important if the lifetimes against long wavelength photochemistry are similar to or shorter than the time for 


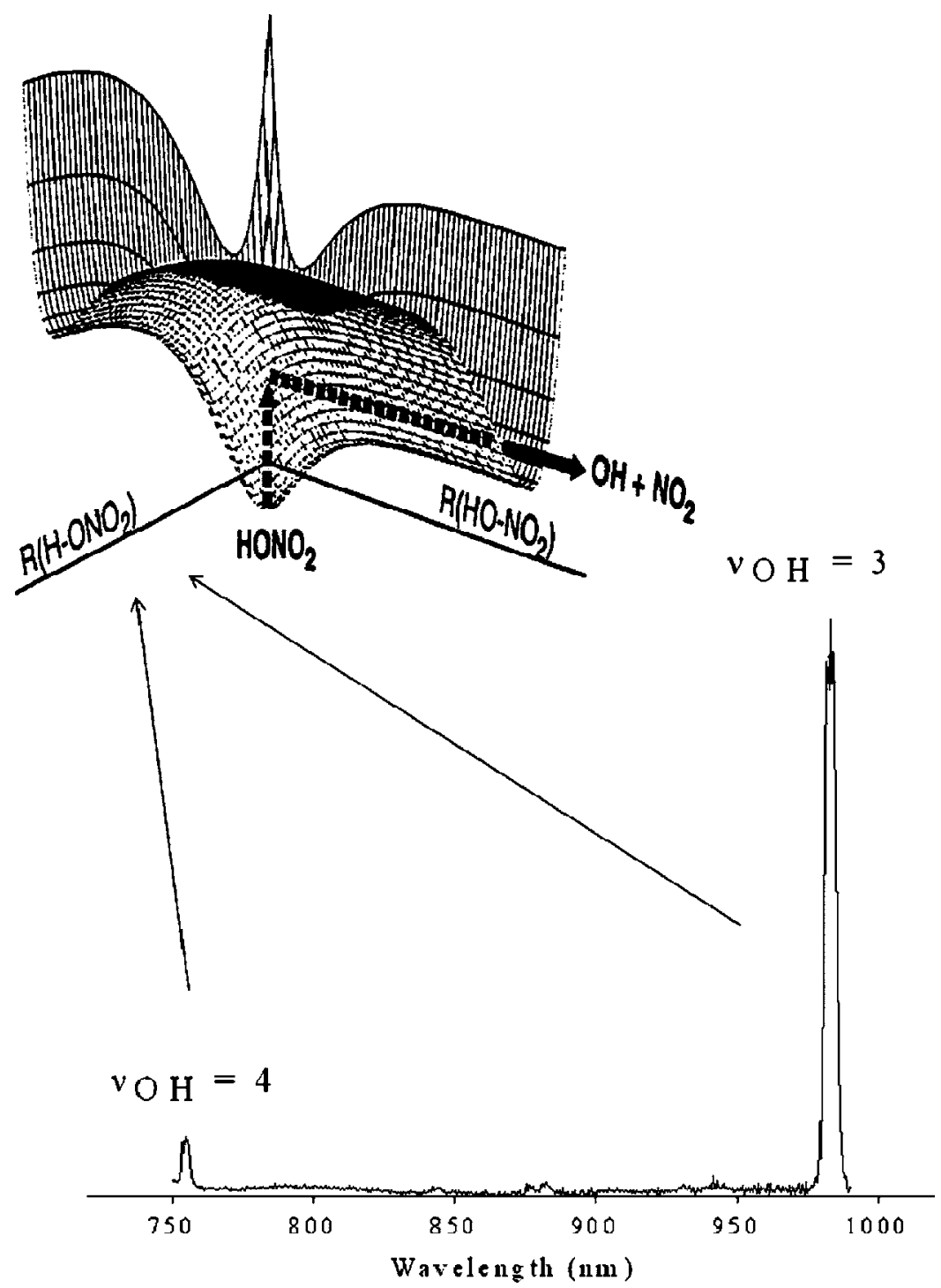

FIGURE 1. An absorption spectrum of gas-phase $\mathrm{HNO}_{3}$, measured in the region of lower-lying $\mathrm{OH}$ vibratinal overtone transitions (lower part) (16). If sufficient energy is intitially deposited into the $\mathrm{OH}$ stretch, via absorption, it may be transferred into the $\mathrm{N}-\mathrm{OH}$ stretch, causing bond cleavage. This occurs at the $v=5$ level of $\mathrm{OH}$ stretching (not shown).

scavenging by $\mathrm{H}_{2} \mathrm{O}$ droplets or aerosol particles. This limit may be achieved for reactions having barriers such that excitation into the $v=3$ (or lower) level of an $\mathrm{OH}$ stretch will activate the chemistry.

An interesting wrinkle to the above takes place in the presence of $\mathrm{H}_{2} \mathrm{O}_{(\mathrm{g})}$ : by forming hydrogen-bonded complexes with acids and alcohols, $\mathrm{H}_{2} \mathrm{O}$ can act as a catalyst to many of the elimination reactions $(24,25,30,31)$, lowering the barriers by providing a "hydrogen shuttle" (31). The lower barrier may allow excitation of lower $\mathrm{OH}$ vibrational levels, which absorb more strongly, to activate the chemistry. Calculated equilibrium constants for such complexes in the troposphere indicate a wide range of possible concentrations, with fractions of the acid or alcohol sequestered in $\mathrm{a}_{2} \mathrm{O}$ complex from $\sim 10^{-4}$ to $0.1(22,24,25,30)$. Combining the increase in the photochemical rate (due to lower vibrational levels becoming important) with the calculated fraction of complexes suggests that this catalyzed chemistry may be as important or more important than the uncatalyzed process. The result, which has not yet been tested experimentally, is that under these conditions, the environmental fates of compounds such as perfluoroalcohols, $\alpha$-hydroxy acids, and organic diacids may be governed by overtone photochemistry.

\section{Photocatalyzed Processes}

Another manner in which longer wavelength radiation may induce chemical reaction is through a photosensitized process, in which compound $A$, associated with a surface exposed to the atmosphere, absorbs long wavelength light and subsequently transfers sufficient energy to compound $B$, which does not absorb such light, thus causing a chemical transformation. For example, in natural waters, dissolved organic matter (DOM) absorbs visible and near-UV radiation and transfers energy to dissolved $\mathrm{O}_{2}$, forming "singlet oxygen", which reacts with the DOM to yield $\mathrm{OH} \cdot(32)$. Thus $\mathrm{O}_{2}$, which does not absorb actinic radiation, may be activated indirectly. Another example is visible light absorption by particles of $\mathrm{TiO}_{2}$, which creates negative electrons and positive "holes" near that semiconductor's surface. The availability of these highly reactive species gives rise to heterogeneous redox reactions, notably the production of $\mathrm{OH}$ from water molecules present at the $\mathrm{TiO}_{2}$ surface.

Similar redox chemistry is initiated by biogenic compounds exposed to the atmosphere, in aerosol particles, or at sea and lake surfaces. Chlorophyll is a strongly photoactive compound: it absorbs light throughout the visible part of the solar spectrum and thus makes electrons available to 


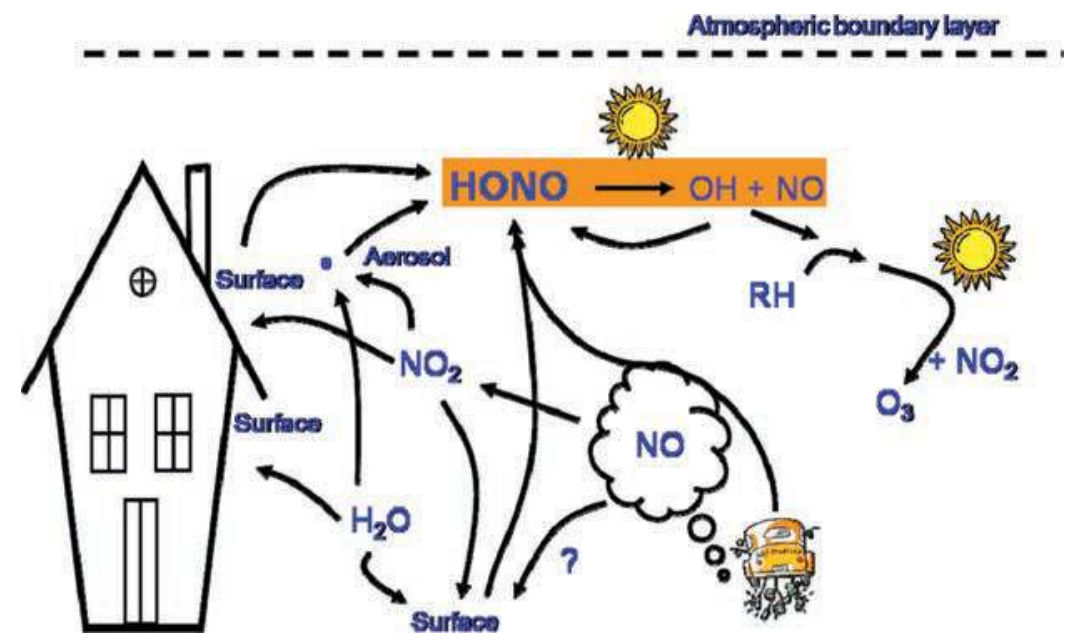

FIGURE 2. A simplified view of how surfaces exposed to the atmosphere (especially in an urban setting) influence nitrogen oxide cycling. In particular, the role of surfaces in transforming (via photosensitized reduction) gas-phase $\mathrm{NO}_{2}$ to $\mathrm{HONO}$ is highlighted.

participate in reduction reactions. When present at salt water surfaces, chlorophyll which is photoexcited (even just with red light) oxidizes halide anions, forming halogen atoms $(33,34)$. Some of these may react with the chlorophyll and other organic compounds present at the water surfaces and forming gas, leading to the release of lighter organics from such surfaces, forming gas-phase radicals; others are released into the gas phase directly in atomic or molecular form. But chlorophyll is only one example, as the same photoredox chemistry is observed using benzophenone as the absorbing species (35). This implies that halogen and radical release from seawater may be quite general, as ocean surfaces are known to be coated with a thin layer of biogenic material (the "marine microlayer"), which contains myriad photoactive compounds $(36,37)$. Indeed, recent measurements have indicated the presence of reactive halogen species in the marine boundary layer (38-40).

One method by which atmospheric aerosols affect climate change is via warming by visible light absorption by the particle. The electronic absorption transitions which are responsible for exciting the particle surfaces may then also allow photoreductio, by supplying electrons in the same manner as chlorophyll. For example, on illuminated mineral dust, humic, and soot surfaces, $\mathrm{NO}_{2}$ undergoes heterogeneous reduction to $\mathrm{HONO}$, with over $50 \%$ efficiency-and in the case of humic acids, an efficiency approaching 100\% (41-43). $\mathrm{HONO}$ is an important source for $\mathrm{OH}$ in the atmosphere, as it is rapidly photolyzed by near-UV radiation, at wavelengths longer than required for reactions $\mathrm{R} 1$ and $\mathrm{R} 4$. Thus, the photoreduction of $\mathrm{NO}_{2}$ gives a long wavelength source for $\mathrm{OH}$, while perturbing only a little (due to the relative importance of R7vs R8) the photostationary state relationship between $\mathrm{NO}_{2}$ and $\mathrm{O}_{3}$ :

$$
\begin{gathered}
\mathrm{NO}+\mathrm{O}_{3} \rightarrow \mathrm{NO}_{2}+\mathrm{O}_{2} \\
\mathrm{NO}_{2}+\mathrm{O}_{2}+\mathrm{h} v \rightarrow \mathrm{NO}+\mathrm{O}_{3} \\
\mathrm{NO}_{2}+\mathrm{h} v(\text { heterogenous }) \rightarrow \mathrm{HONO} \\
\mathrm{HONO}+\mathrm{h} v(\lambda<390 \mathrm{~nm}) \rightarrow \mathrm{OH}+\mathrm{NO}
\end{gathered}
$$

This chemistry does not occur in the dark to any appreciable extent, but is induced via absorption of actinic radiation by the solid substrate. Although a recent report suggests that electronically excited $\mathrm{NO}_{2}$ may react efficiently to form HONO in the gas phase $(44,45)$, this finding is the subject of considerable debate $(46,47)$. For the heterogeneous process on all three substrates listed above, the photore- duction persists over several hours without loss of efficiency. This implies that the substrate itself is not being depleted through supplying the $\mathrm{H}$ during the reduction $\mathrm{R} 8$, but that there exists another source of $\mathrm{H}$ atoms. In the atmosphere this is most probably adsorbed water, which is present ubiquitously on surfaces in the real atmosphere.

A semiquantitative estimate of the importance of such photosensitized chemistry can be estimated from the results of Stemmler et al. (43) who studied the photoenhanced deposition of $\mathrm{NO}_{2}$ on humic acid and soil surfaces. In the presence of $16.5 \mathrm{ppb} \mathrm{NO}_{2}$ they observed a photoinduced HONO flux of $2.5 \times 10^{10}$ molecules $\mathrm{cm}^{2} \mathrm{~s}^{-1}$ under UV-A irradiation and $1 \times 10^{10}$ molecules $\mathrm{cm}^{-2} \mathrm{~s}^{-1}$ in the visible region. Using these results, and scaling for the lamp intensities, the total photochemical HONO production may be estimated to be $\sim 5 \times 10^{10}$ molecules $\mathrm{cm}^{-2} \mathrm{~s}^{-1}$ for a moderately polluted atmosphere $\left(\sim 20 \mathrm{ppb} \mathrm{NO}_{2}\right.$, which is an abundance typically reached daily in urban centers) and typical midday solar irradiances $(300-700 \mathrm{~nm}) \sim 400 \mathrm{Wm}^{-2}$. Since such surfaces are ubiquitous in the environment, this process can lead to high daytime concentrations of HONO; the flux estimates above predict that such processes could account for up to $60 \%$ of the integrated $\mathrm{OH}$ radical source strength, overwhelming reactions R1 to R5 in importance and suggesting that this chemistry may be observed in field measurements. These ideas are captured in Figure 2, which illustrates how surface photochemistry influences $\mathrm{OH}$ production in urban settings.

Mineral dust surfaces are also important substrates for photosensitized chemistry. Every year between 1000 and 3000 Tg of mineral aerosol are emitted globally and injected into the atmosphere. Ndour et al. (42) demonstrated that these surfaces are photochemically active under atmospherically relevant conditions, giving rise to a large photoenhanced uptake of $\mathrm{NO}_{2}$. Simulations with the LMDz-INCA model indicated that such mineral dust photochemistry may reduce the $\mathrm{NO}_{2}$ level up to $37 \%$ during a dust event in the free troposphere, causing a change in the $\mathrm{O}_{3}$ concentration of $5 \%$ (42). When averaged over the globe, the decrease in simulated $\mathrm{NO}_{2}$ concentrations in the free troposphere amounts to $3.0 \%$.

\section{Outlook: Reevaluating Atmospheric Cleansers!}

Could long wavelength photochemistry help clean the atmosphere? The examples discussed above suggest that this could well be! By enhancing the production of $\mathrm{HO}_{x}$ radicals which initiate the degradation reactions of atmospheric pollutants, these photochemical mechanisms could have a significant impact on atmospheric processes. Assessing the 
full extent to which they influence the atmosphere will certainly require further research. We need to know how general surface photochemistry processes are. They may indeed affect a variety of deposition processes, which are mostly seen as being sinks for atmospheric trace compounds. If these supposed sinks are in fact photochemically driven processes, there may be an enhanced interplay between gaseous components and condensed matter (i.e., at ground or airborne particles) as highlighted by the example of $\mathrm{NO}_{2}$ deposition on soil being a sink for $\mathrm{NO}_{2}$ but a source of $\mathrm{HONO}$.

In the atmosphere, all photochemical reactions occur against a "clock" set by collisional deactivation of the excited species generated by absorbing light. If a reaction is too slow, with a time constant similar to or larger than that for collisional deactivation, the absorbed energy will be dissipated by collisions, predominantly with $\mathrm{N}_{2}$ and $\mathrm{O}_{2}$. Because the collision frequency decreases significantly with increasing altitude, there is an altitude dependence to the efficiency of atmospheric photochemical processes. In the stratosphere, even slow reactions can proceed efficiently as was shown for red-light initiated $\mathrm{HO}_{x}$ production from pernitric acid in the stratosphere. At the lower altitudes where most organic chemistry takes place, the yield and importance of overtoneinitiated photochemical processes will depend on the relative rates of energy flow and reaction, vs energy loss by collisions. Understanding the mechanisms and dynamics of overtoneinitiated and photosensitized reactions remain important challenges for the future. As the atmosphere is the venue of gas-phase chemistry, these fundamentals are vital to our ability to understand and predict air pollution and climate change.

James Donaldson is a Professor of Chemistry at the University of Toronto. Christian George is a senior research scientist at IRCELYON (CNRS and Université de Lyon 1). Veronica Vaida is a Professor of Chemistry and a CIRES Fellow at the University of Colorado. Please address correspondence to jdonalds@chem.utoronto.ca.

\section{Acknowledgments}

We thank several funding agencies for supporting our various efforts in "red sky" chemistry. V.V. acknowledges NSF support, C.G. thanks CNRS and the French Science Ministry, and D.J.D. thanks NSERC and the European Science Foundation for the award of an exchange grant through the INTROP scientific programme.

\section{Literature Cited}

(1) Levy, H. Normal Atmosphere - Large radical and formaldehyde concentrations predicted. Science 1971, 173 (3992), 141-\&.

(2) Finlayson-Pitts, B.; Pitts, J. J. Chemistry of the Upper and Lower Atmosphere; Academic Press: New York, 2000.

(3) Wennberg, P. O. Atmospheric chemistry - Radicals follow the sun. Nature 2006, 442 (7099), 145-146.

(4) Wennberg, P. O.; Salawitch, R. J.; Donaldson, D. J.; Hanisco, T. F.; Lanzendorf, E. J.; Perkins, K. K.; Lloyd, S. A.; Vaida, V.; Gao, R. S.; Hintsa, E. J.; Cohen, R. C.; Swartz, W. H.; Kusterer, T. L.; Anderson, D. E. Twilight observations suggest unknown sources of HOx. Geophys. Res. Lett. 1999, 26 (10), 1373-1376.

(5) Lelieveld, J.; Butler, T. M.; Crowley, J. N.; Dillon, T. J.; Fischer, H.; Ganzeveld, L.; Harder, H.; Lawrence, M. G.; Martinez, M.; Taraborrelli, D.; Williams, J. Atmospheric oxidation capacity sustained by a tropical forest. Nature 2008, 452 (7188), 737-740.

(6) Hofzumahaus, A.; Rohrer, F.; Lu, K. D.; Bohn, B.; Brauers, T.; Chang, C. C.; Fuchs, H.; Holland, F.; Kita, K.; Kondo, Y.; Li, X.; Lou, S. R.; Shao, M.; Zeng, L. M.; Wahner, A.; Zhang, Y. H. Amplified Trace Gas Removal in the Troposphere. Science 2009, 324 (5935), 1702-1704.

(7) Wennberg, P. O.; Cohen, R. C.; Stimpfle, R. M.; Kopolow, J. P.; Anderson, J. G.; Salawitch, R. J.; Fahey, D. W.; Woodbridge, E. L.; Keim, E. R.; Gao, R. S.; Webster, C. R.; May, R. D.; Toohey, D. W.; Avallone, L. M.; Proffitt, M. H.; Lowenstein, M.; Podolske, J. R.; Chan, K. R.; Wofsy, S. C. Removal of stratospheric $\mathrm{O}_{3}$ by radicals. In situ measurements of $\mathrm{OH}, \mathrm{HO}_{2}, \mathrm{NO}, \mathrm{NO}_{2}, \mathrm{ClO}$ and BrO. Science 1994, 266 (5184), 389-404.
(8) Donaldson, D. J.; Frost, G. J.; Rosenlof, K. H.; Tuck, A. F.; Vaida, V. Atmospheric radical production by excitation of vibrational overtones via absorption of visible light. Geophys. Res. Lett. 1997, 24 (21), 2651-2654.

(9) Murphy, J. G.; Thornton, J. A.; Wooldridge, P. J.; Day, D. A.; Rosen, R. S.; Cantrell, C.; Shetter, R. E.; Lefer, B.; Cohen, R. C. Measurements of the sum of $\mathrm{HO}_{2} \mathrm{NO}_{2}$ and $\mathrm{CH}_{3} \mathrm{O}_{2} \mathrm{NO}_{2}$ in the remote troposphere. Atmos. Chem. Phys. 2004, 4, 377-384.

(10) Salawitch, R. J.; Wennberg, P. O.; Toon, G. C. Near IR photolysis of $\mathrm{HO}_{2} \mathrm{NO}_{2}$ : Implications for HOx. Geophys. Res. Lett. 2002, 29 (16), Article 1762.

(11) Stark, H.; Brown, S. S.; Burkholder, J. B.; Aldener, M.; Riffault, V.; Gierczak, T.; Ravishankara, A. R. Overtone dissociation of peroxynitric acid $\left(\mathrm{HO}_{2} \mathrm{NO}_{2}\right)$ : Absorption cross sections and photolysis products. J. Phys. Chem. A 2008, 112 (39), 9296-9303.

(12) Zhang, H.; Roehl, C. M.; Sander, S. P. Intensity of the second and third $\mathrm{OH}$ overtones of $\mathrm{H}_{2} \mathrm{O}_{2}, \mathrm{HNO}_{3}$ and $\mathrm{HO}_{2} \mathrm{NO}_{2}$. J. Geophys. Res., [Atmos.] 2000, 105 (D11), 14593-14598.

(13) Crim, F. F. Selective excitation studies of unimolecular reaction dynamics. Annu. Rev. Phys. Chem. 1984, 35, 657-691.

(14) Donaldson, D. J.; Tuck, A. F.; Vaida, V. Atmospheric photochemistry via vibrational overtone absorption. Chem. Rev. 2003, 103 (12), 4717-4729.

(15) Henry, B. R. Local modes in description of highly vibrationally excited molecules. Acc. Chem. Res. 1977, 10 (6), 207-213.

(16) Donaldson, D. J.; Orlando, J. J.; Amann, S.; Tyndall, G. S.; Proos, R. J.; Henry, B. R.; Vaida, V. Absolute intensities of nitric acid overtones. J. Phys. Chem. A 1998, 102 (27), 5171-5174.

(17) Matthews, J.; Fry, J. L.; Roehl, C. M. Vibrational overtone initiated unimolecular dissociation of $\mathrm{HOCH}_{2} \mathrm{OOH}$ and $\mathrm{HOCD}_{2} \mathrm{OOH}$ : Evidence for mode selective behavior. J. Chem. Phys. 2008, 128 (18), Article 184306.

(18) Miller, Y.; Chaban, G. M.; Finlayson-Pitts, B. J.; Gerber, R. B. Photochemical processes induced by vibrational overtone excitations: Dynamics symulations for cis-HONO, trans-HONO, $\mathrm{HNO}_{3}$, and $\mathrm{HNO}_{3}-\mathrm{H}_{2} \mathrm{O}$. J. Phys. Chem. A 2006, 110 (16), 53425354.

(19) Donaldson, D. J.; Tuck, A. F.; Vaida, V. Enhancement of HOx at high solar zenith angles by overtone-induced dissociation of $\mathrm{HNO}_{3}$ and $\mathrm{HNO}_{4}$. Phys. Chem. Earth Part C 2000, 25 (3), 223227.

(20) Miller, Y.; Gerber, R. B.; Vaida, V. Photodissociation yields for vibrationally excited states of sulfuric acid under atmospheric conditions. Geophys. Res. Lett. 2007, 34, (16).

(21) Mills, M. J.; Toon, O. B.; Vaida, V.; Hintze, P. H.; Kjaergaard, H. G.; Schofield, D. P.; Robinson, T. W. Photolysis of sulfuric acid vapor by visible light as a source of the polar stratospheric CN layer. J. Geophys. Res., [Atmos.] 2005, 110, D08201.

(22) Vaida, V.; Kjaergaard, H. G.; Hintze, P. E.; Donaldson, D. J. Photolysis of sulfuric acid vapor by visible solar radiation. Science 2003, 299 (5612), 1566-1568.

(23) Reynard, L. M.; Donaldson, A. J. Overtone-induced chemistry of trifluoroacetic acid: An experimental and theoretical study. J. Phys. Chem. A 2002, 106 (37), 8651-8657.

(24) Young, C. J.; Donaldson, D. J. Overtone-induced degradation of perfluorinated alcohols in the atmosphere. J. Phys. Chem. A 2007, 111 (51), 13466-13471.

(25) Staikova, M.; Oh, M.; Donaldson, D. J. Overtone-induced decarboxylation: A potential sink for atmospheric diacids. J. Phys. Chem. A 2005, 109 (4), 597-602.

(26) Takahashi, K.; Plath, K. L.; Skodje, R. T.; Vaida, V. Dynamics of vibrational overtone excited pyruvic acid in the gas phase: Line broadening through hydrogen-atom chattering. J. Phys. Chem. A 2008, 112 (32), 7321-7331.

(27) Plath, K. L.; Takahashi, K.; Skodje, R. T.; Vaida, V. Fundamental and Overtone Vibrational Spectra of Gas-Phase Pyruvic Acid. J. Phys. Chem. A 2009, 113 (26), 7294-7303.

(28) Plath, K. L.; Axson, J. L.; Nelson, G. C.; Takahashi, K.; Skodje, R. T.; Vaida, V. Gas-phase vibrational spectra of glyoxylic acid and its gem diol monohydrate. Implications for atmospheric chemistry. React. Kinet. Catal. Lett. 2009, 96 (2), 209-224.

(29) Takahashi, K.; Plath, K. L.; Axson, J. L.; Nelson, G. C.; Skodje, R. T.; Vaida, V. Dynamics and spectroscopy of vibrational overtone excited glyoxylic acid and 2,2-dihydroxyacetic acid in the gas-phase. J. Phys. Chem. A 2010, 132, DOI: 10.1021/094305.

(30) Staikova, M.; Donaldson, D. J. Water complexes as catalysts in atmospheric reactions. Phys. Chem. Earth Part C 2001, 26 (7), 473-478.

(31) Takahashi, K.; Kramer, Z. C.; Vaida, V.; Skodje, R. T. Vibrational overtone induced elimination reactions within hydrogen- 
bonded molecular clusters: the dynamics of water catalyzed reactions in $\mathrm{CH}_{2} \mathrm{FOH} \cdot\left(\mathrm{H}_{2} \mathrm{O}\right)$. Phys. Chem. Chem. Phys. 2007, 9 (29), 3864-3871.

(32) Schwarzenbach, R. P.; Gschwend, P. M.; Imboden, D. M. Environmental Organic Chemistry, 2nd ed.; Wiley-Interscience: New York, 2003.

(33) Reeser, D. I.; George, C.; Donaldson, D. J. Photooxidation of Halides by Chlorophyll at the Air-Salt Water Interface. J. Phys. Chem. A 2009, 113 (30), 8591-8595.

(34) Reeser, D. I.; Jammoul, A.; Clifford, D.; Brigante, M.; D’Anna, B.; George, C.; Donaldson, D. J. Photoenhanced Reaction of Ozone with Chlorophyll at the Seawater Surface. J. Phys. Chem. C 2009, 113 (6), 2071-2077.

(35) Jammoul, A.; Dumas, S.; D’Anna, B.; George, C. Photoinduced oxidation of sea salt halides by aromatic ketones: a source of halogenated radicals. Atmos. Chem. Phys. 2009, 9 (13), 42294237.

(36) Hardy, J. T. The sea-surface microlayer: biology, chemistry and anthropogenic enrichment. Prog. Oceanogr. 1982, 11,307328.

(37) Liss, P. S.; Duce, R. A. The Sea Surface and Global Change; Cambridge University Press: Cambridge, 1997.

(38) Finley, B. D.; Saltzman, E. S. Observations of Cl-2, Br-2, and I-2 in coastal marine air. J. Geophys. Res., [Atmos.] 2008, 113 (D21), 14.

(39) Read, K. A.; Mahajan, A. S.; Carpenter, L. J.; Evans, M. J.; Faria, B. V. E.; Heard, D. E.; Hopkins, J. R.; Lee, J. D.; Moller, S. J.; Lewis, A. C.; Mendes, L.; McQuaid, J. B.; Oetjen, H.; Saint-Lopez, A.; Pilling, M. J.; Plane, J. M. C. Extensive halogen-mediated ozone destruction over the tropical Atlantic Ocean. Nature 2008, 453 (7199), 1232-1235.

(40) Mahajan, A. S.; Oetjen, H.; Saiz-Lopez, A.; Lee, J. D.; McFiggans, G. B.; Plane, J. M. C. Reactive iodine species in a semi-polluted environment. Geophys. Res. Lett. 2009, 36, 6.

(41) George, C.; Strekowski, R. S.; Kleffmann, J.; Stemmler, K.; Ammann, M. Photoenhanced uptake of gaseous $\mathrm{NO}_{2}$ on solidorganic compounds: a photochemical source of HONO? Faraday Discuss. 2005, 130, 195-210.

(42) Ndour, M.; D’Anna, B.; George, C.; Ka, O.; Balkanski, Y.; Kleffmann, J.; Stemmler, K.; Ammann, M. Photoenhanced uptake of $\mathrm{NO}_{2}$ on mineral dust: Laboratory experiments and model simulations. Geophys. Res. Lett. 2008, 35 (5), 5.

(43) Stemmler, K.; Ammann, M.; Donders, C.; Kleffmann, J.; George, C. Photosensitized reduction of nitrogen dioxide on humic acid as a source of nitrous acid. Nature 2006, 440 (7081), 195-198.

(44) Li, S. P.; Matthews, J.; Sinha, A. Atmospheric hydroxyl radical production from electronically excited $\mathrm{NO}_{2}$ and $\mathrm{H}_{2} \mathrm{O}$. Science 2008, 319 (5870), 1657-1660.

(45) Wennberg, P. O.; Dabdub, D. Atmospheric chemistry - Rethinking ozone production. Science 2008, 319 (5870), 1624-1625.

(46) Carr, S.; Heard, D. E.; Blitz, M. A. Comment on "Atmospheric Hydroxyl Radical Production from Electronically Excited $\mathrm{NO}_{2}$ and $\mathrm{H}_{2} \mathrm{O}$ ". Science 2009, 324, 5925.

(47) Li, S. P.; Matthews, J.; Sinha, A. Response to Comment on "Atmospheric Hydroxyl Radical Production from Electronically Excited $\mathrm{NO}_{2}$ and $\mathrm{H}_{2} \mathrm{O}$ ". Science 2009, 324, 5925. 